\title{
Immunization with 3-oxododecanoyl-L-homoserine lactone-protein conjugate protects mice from lethal Pseudomonas aeruginosa lung infection
}

\begin{abstract}
Correspondence
Kazuhiro Tateda

kazu@med.toho-u.ac.jp
\end{abstract}

Received 4 April 2006

Accepted 21 June 2006

\author{
Shinichi Miyairi, ${ }^{1}$ Kazuhiro Tateda, ${ }^{2}$ Etsu T. Fuse, ${ }^{2}$ Chihiro Ueda, ${ }^{1}$ \\ Hiroaki Saito, ${ }^{1}$ Tohru Takabatake, ${ }^{1}$ Yoshikazu Ishii, ${ }^{2}$ Manabu Horikawa, ${ }^{3}$ \\ Masaji Ishiguro, ${ }^{3}$ Theodore J. Standiford ${ }^{4}$ and Keizo Yamaguchi ${ }^{2}$ \\ ${ }^{1}$ Laboratory of Bio-organic Chemistry, College of Pharmacy, Nihon University, Chiba 274-8555, \\ Japan \\ ${ }^{2}$ Departments of Microbiology and Infectious Diseases, Toho University School of Medicine, \\ 5-21-16 Ohmorinishi, Ohtaku, Tokyo 143-8540, Japan \\ ${ }^{3}$ Suntory Institute for Bioorganic Research, Osaka 618-8503, Japan \\ ${ }^{4}$ Pulmonary and Critical Care Medicine, University of Michigan Medical School, Ann Arbor, MI \\ 48109-0360, USA
}

\begin{abstract}
Quorum-sensing systems have been reported to play a critical role in the pathogenesis of several bacterial infections. Recent data have demonstrated that Pseudomonas

$\mathrm{N}$-3-oxododecanoyl-L-homoserine lactone (3-oxo- $\mathrm{C}_{12}$-homoserine lactone, 3-oxo- $\mathrm{C}_{12}-\mathrm{HSL}$ ), but not $N$-butanoyl-L-homoserine lactone $\left(\mathrm{C}_{4}-\mathrm{HSL}\right)$, induces apoptosis in macrophages and neutrophils. In the present study, the effects of active immunization with 3-oxo- $\mathrm{C}_{12}-\mathrm{HSL}-$ carrier protein conjugate on acute $P$. aeruginosa lung infection in mice were investigated. Immunization with 3-oxo- $\mathrm{C}_{12}-\mathrm{HSL}-\mathrm{BSA}$ conjugate (subcutaneous, four times, at 2-week intervals) elaborated significant amounts of specific antibody in serum. Control and immunized mice were intranasally challenged with approximately $3 \times 10^{6}$ c.f.u. $P$. aeruginosa PAO1, and survival was then compared. All control mice died by day 2 post bacterial challenge, while $36 \%$ of immunized mice survived to day $4(P<0.05)$. Interestingly, bacterial numbers in the lungs did not differ between control and immunized groups, whereas the levels of pulmonary tumour necrosis factor (TNF) $-\alpha$ in the immunized mice were significantly lower than those of control mice $(P<0.05)$. Furthermore, the extractable 3-oxo- $\mathrm{C}_{12}-\mathrm{HSL}$ levels in serum and lung homogenate were also significantly diminished in the immunized mice. Immune serum completely rescued reduction of cell viability by $3-$ oxo- $\mathrm{C}_{12}-\mathrm{HSL}$-mediated apoptosis in macrophages in vitro. These results demonstrated that specific antibody to 3 -oxo- $\mathrm{C}_{12}-\mathrm{HSL}$ plays a protective role in acute $P$. aeruginosa infection, probably through blocking of host inflammatory responses, without altering lung bacterial burden. The present data identify a promising potential vaccine strategy targeting bacterial quorum-sensing molecules, including autoinducers.
\end{abstract}

\section{INTRODUCTION}

Pseudomonas aeruginosa is an opportunistic pathogen that causes a wide range of acute and chronic infections, including sepsis, and wound and pulmonary infections (Richards et al., 1999). This organism is known to produce a variety of virulence factors, such as pigments, proteases and exotoxins. The synthesis of these factors is regulated by

Abbreviations: $\mathrm{C}_{4}-\mathrm{HSL}, \mathrm{N}$-butanoyl-L-homoserine lactone; HRP, horseradish peroxidase; HSL, homoserine lactone; IL, interleukin; OV, ovalbumin; 3-oxo- $\mathrm{C}_{12}$-HSL, N-3-oxododecanoyl-L-homoserine lactone; TNF, tumour necrosis factor. a cell-to-cell signalling mechanism referred to as quorum sensing (Fuqua et al., 1994), which was originally described in Vibrio fischeri as a LuxR/LuxI-type system (Kaplan \& Greenberg, 1985). LasRI and RhlRI are known to be two major quorum-sensing components in $P$. aeruginosa, and this mechanism enables bacteria to coordinately turn on and turn off genes in a density-dependent manner by the production of small diffusible molecules called autoinducers (Van Delden \& Iglewski, 1998). P. aeruginosa predominately produces two autoinducers, $\mathrm{N}$-3-oxododecanoyl-L-homoserine lactone (3-oxo- $\mathrm{C}_{12}$-HSL) and N-butanoyl-L-homoserine lactone ( $\left.\mathrm{C}_{4}-\mathrm{HSL}\right)$ (Pearson et al., 1994, 1995). The expression of autoinducer-regulated virulence factors 
directly contributes to the colonization and dissemination of the bacteria, and this may determine the course and outcome in individuals infected with P. aeruginosa (Miller \& Bassler, 2001; Smith \& Iglewski, 2003a; Whitehead et al., 2001).

Recent progress in quorum-sensing research has demonstrated that Pseudomonas homoserine lactones (HSLs) are not only important in the regulation of bacterial virulence genes but also interact with eukaryotic cells and modulate immune responses (DiMango et al., 1995; Saleh et al., 1999; Telford et al., 1998). Stimulation with 3-oxo-C $\mathrm{C}_{12}$-HSL induces production of the chemokine interleukin (IL)-8 in human lung structural cells, such as fibroblasts and bronchial epithelial cells (Smith et al., 2001). More recently, it has been reported that 3-oxo- $\mathrm{C}_{12}$-HSL induces cyclooxygenase- 2 and prostaglandin $\mathrm{E}_{2}$ production in human lung fibroblasts, suggesting a pivotal role for 3-oxo- $\mathrm{C}_{12}$-HSL in inflammation (Smith et al., 2002). On this point, we have reported that Pseudomonas 3-oxo- $\mathrm{C}_{12}-\mathrm{HSL}$, but not $\mathrm{C}_{4}$ HSL, induces apoptosis in macrophages and neutrophils (Tateda et al., 2003). These data suggest that autoinducer molecules at the site of infection contribute not only to the expression of bacterial virulence factors, but also to the modulation of host defence systems.

Since the 1960s, a number of experimental vaccines have been developed and tested for the prevention of $P$. aeruginosa infections in animals and patients. A variety of bacterial products (toxins, exopolysaccharide) and cell surface structures (LPS, outer-membrane proteins, flagella, type III secretion apparatus) have been examined for their potential as vaccine targets against $P$. aeruginosa infection (Baumann et al., 2004; Cachia \& Hodges, 2003; Mrsny et al., 2002; Thomas et al., 2003). The most promising of the products tested have been vaccines based on LPS as antigens, named Pseudogen and PEV-01. These have proved to be effective in certain individuals, such as patients with burns, cystic fibrosis and malignancies, although the toxicity associated with the lipid A fraction of LPS has prevented approval for routine clinical use of these products (Cryz et al., 1987; Jones et al., 1979; Pier, 1982). Sawa and collaborators have reported a type III secretion apparatus, PcrV, a unique system that injects bacterial toxin into eukaryotic cells, as a new vaccine target, and immunization against $\mathrm{PcrV}$ ensures the survival of challenged mice and decreased lung inflammation and injury (Sawa et al., 1999). More recently, the protective efficacy of DNA vaccines against outer-membrane protein $\mathrm{F}$ has been reported in a mouse model of chronic lung infection due to $P$. aeruginosa (Price et al., 2002; Staczek et al., 2003). However, there is currently no approved vaccine against $P$. aeruginosa infections in the clinical setting. Recently, several investigators have suggested quorum-sensing systems as a new area to search for novel types of vaccine candidate, although no data have been reported to date (Smith \& Iglewski, 2003b; Suga \& Smith, 2003). In particular, blocking of bacterial autoinducer molecules by means of active and passive immunization is believed to be a promising strategy for treatment of $P$. aeruginosa infections.

In the present study, we investigated the effects of active immunization with carrier-conjugated 3 -oxo- $\mathrm{C}_{12}$-HSL on the lethality of acute $P$. aeruginosa lung infection in mice. Also, we examined the effects of blocking antibody on bacterial numbers and cytokine levels in the infected lungs.

\section{METHODS}

Mice and bacteria used. $\mathrm{BALB} / \mathrm{c}$ mice were purchased from Charles River Japan. All mice were housed in specific pathogen-free conditions within the animal care facility at the Toho University School of Medicine. Mice were 6-8 weeks old at the start of the experiments. We used $P$. aeruginosa PAO1 strain (a generous gift from B. H. Iglewski, University of Rochester School of Medicine and Dentistry) for pulmonary infection in mice (Tateda et al., 2001).

Preparation of protein-conjugated 3-oxo- $\mathbf{C}_{12}$-HSL. 3-oxo- $\mathrm{C}_{12^{-}}$ HSL was chemically synthesized as previously described (Fig. 1; Tateda et al., 2003). The molecule is structurally and functionally identical to those obtained from $P$. aeruginosa cultures. The compound was shown to be pure by HPLC. The absence of detectable levels of endotoxin in preparations was verified by a Limulus amoebocyte lysate assay. $\mathrm{N}$-(12-(3-Carboxypropionyl)oxy-3-oxododecanoyl) HSL was synthesized as a hapten by the method described previously (Horikawa et al., 2006). The conjugation reaction of the hapten to BSA was carried out by the activated ester method (Hosoda et al., 1979). A mixture of the hapten $(26.3 \mathrm{mg})$, $\mathrm{N}$-hydroxysuccinimide (Tokyo-Kasei Kogyo) $(8.8 \mathrm{mg}$ ) and 1-ethyl3-(3-dimethylaminopropyl) carbodiimide hydrochloride (water soluble carbodiimide, WSC) $(27 \mathrm{mg})$ in dioxane $(0 \cdot 8 \mathrm{ml})$ was stirred at $18-24^{\circ} \mathrm{C}$ for $6 \mathrm{~h}$. The resulting activated ester solution $(274 \mu \mathrm{l})$ was diluted with $2 \mathrm{ml} 50 \mathrm{mM}$ potassium phosphate buffer, $\mathrm{pH} 7 \cdot 4$ (KPi), and BSA solution [40 mg BSA (Sigma) in $1 \mathrm{ml} \mathrm{KPi]} \mathrm{was}$ added. The whole mixture was stirred at $4{ }^{\circ} \mathrm{C}$ for $2 \cdot 5$ days. Then, the resulting mixture was subjected to dialysis against saline and stored at $-85^{\circ} \mathrm{C}$ until use. The hapten was also conjugated with ovalbumin (OV; Sigma) in a similar manner to the immobilized antigen.

Immunization protocol and measurement of specific antibody titre to 3-oxo- $\mathbf{C}_{\mathbf{1 2}}-\mathbf{H S L}$. Mice were subcutaneously injected with 3-oxo- $\mathrm{C}_{12}$-HSL-BSA with Freund's complete adjuvant for the priming, and incomplete adjuvant for boost (three times at 2-week intervals). The serum antibody titre to 3 -oxo- $\mathrm{C}_{12}$-HSL was examined using the immobilized antigen. Briefly, 96-well microplates were coated with 3-oxo- $\mathrm{C}_{12}$-HSL-OV conjugate overnight. After serial dilutions of serum with PBS, samples were added to wells and incubated overnight at $4{ }^{\circ} \mathrm{C}$. After washing with PBS three times, horseradish peroxidase (HRP)-labelled anti-mouse $\operatorname{IgG}$ antibody was added to each well and incubated for $4 \mathrm{~h}$ at room temperature.

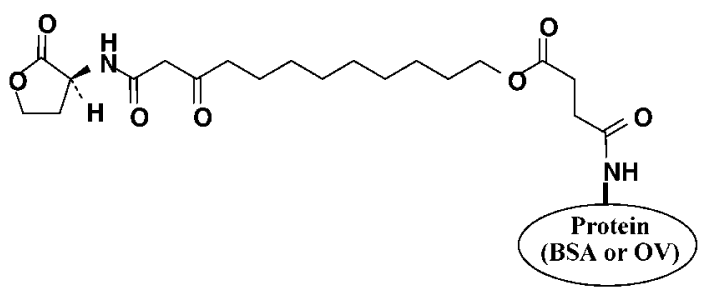

Fig. 1. Structure of the $3-\mathrm{oxo}_{\mathrm{O}}-\mathrm{C}_{12}-\mathrm{HSL}-$ carrier protein conjugate. 
Colour-developing substrate was added to the wells after the removal of unbound HRP-labelled antibody by washing with PBS $A_{590}$ was examined in an auto-reader.

Pulmonary $\boldsymbol{P}$. aeruginosa infection in mice. Bacteria were grown in Mueller-Hinton medium overnight, and diluted to appropriate concentrations in saline. Mice were anaesthetized intramuscularly with $7 \mathrm{mg}$ ketamine and $15 \mathrm{mg}$ xylazine per kilogram of animal, as described previously (Tateda et al., 1996). Bacterial suspension $(30 \mu \mathrm{l})$ was administered intranasally, and survival was monitored twice a day for 7 days after infection.

Bacterial number and tumour necrosis factor (TNF)- $\alpha$ in the lungs. At $24 \mathrm{~h}$ after infection, the mice were killed by $\mathrm{CO}_{2}$ asphyxia and blood was collected to obtain serum. Before lung removal, the pulmonary vasculature was perfused with $1 \mathrm{ml}$ saline via the right ventricle. After removal, whole lungs were homogenized in $1.0 \mathrm{ml}$ saline using a tissue homogenizer (Omni International) under a vented hood. Portions of homogenate $(10 \mu \mathrm{l})$ were inoculated on Mueller-Hinton agar after serial 1:10 dilutions with saline. The remaining homogenates were stood on ice for $30 \mathrm{~min}$, then centrifuged at 2500 r.p.m. for $10 \mathrm{~min}$. Supernatants were collected, passed through a $0.45 \mu \mathrm{m}$ pore-size filter (Kanto Chemical), then stored at $-20{ }^{\circ} \mathrm{C}$ for the assessment of TNF- $\alpha$ and free 3 -oxo- $\mathrm{C}_{12}$-HSL. The level of TNF- $\alpha$ in the lung homogenates was determined using an ELISA kit (Duo Set, ELISA development system; R\&D Systems), according to the manufacturer's directions.

3-Oxo- $\mathbf{C}_{\mathbf{1 2}}$-HSL levels in serum and lung. The 3 -oxo- $\mathrm{C}_{12}-\mathrm{HSL}$ levels in serum and lung homogenate were determined by ELISA. Briefly, the ELISA system was constructed with the specific anti-3oxo- $\mathrm{C}_{12}$-HSL antibody prepared in these laboratories with a rabbit, hapten-OV conjugate-coated 96-well microplates and HRP-labelled goat anti-rabbit IgG antibody (Bio-Rad). The substrate for HRP was $o$-phenylenediamine. Ethyl acetate extracts of the serum and supernatant of lung homogenate were subjected to the ELISA. The 3-oxo$\mathrm{C}_{12}$-HSL extractable by ethyl acetate was mainly in the free fraction rather than in the fraction bound to antibody, and this was confirmed by ultrafiltration using Vivaspin 5000 (Vivascience), which cut off the protein fraction with a molecular mass higher than $5000 \mathrm{Da}$.

Effects of immune serum on apoptosis of macrophages by 3-oxo- $\mathbf{C}_{\mathbf{1 2}}$-HSL. Macrophage cell line P388D1 was grown in RPMI medium supplemented with $10 \%$ fetal calf serum. Cells were seeded at $10^{5}$ cells per well of a 96-well microplate. Twenty-four hours later, cells were treated with $50 \mu \mathrm{M} 3$-oxo- $\mathrm{C}_{12}$-HSL for induction of apoptosis in the presence of immune or non-immune serum. The viability of cells treated with Pseudomonas HSL was measured by using TetraColor ONE (Seikagaku Kogyo), following the manufacturer's instructions (Tateda et al., 2003). At the indicated time points, $10 \mu \mathrm{l}$ of this reagent was added to each well and incubated for an additional $4 \mathrm{~h}$. $\mathrm{A}_{450}$ was monitored, and the percentage viability of the cells was calculated in comparison with that of control non-treated cells.

Statistical analysis. Statistical significance was determined using the unpaired, two-tailed alternate Welsh $t$ test and the nonparametric Mann-Whitney test. Calculations were performed using InStat for Macintosh (GraphPad Software).

\section{RESULTS}

\section{Specific antibody titre to $3-0 \times 0-\mathrm{C}_{12}-\mathrm{HSL}$ after immunization}

After four episodes of boost immunization at 2-week intervals, we examined antibody titres in the serum of mice (no treatment, adjuvant alone and immunized). The serum of mice treated with adjuvant alone showed no increase in antibody titres compared to control mice serum. On the other hand, as expected, immunization with 3 -oxo- $\mathrm{C}_{12^{-}}$ HSL-BSA conjugate strongly induced specific antibody in mice (Fig. 2). An increase of antibody titre of more than 100 times was demonstrated in the serum of immunized mice.

\section{Survival of immunized and non-immunized mice after intranasal inoculation with $\boldsymbol{P}$. aeruginosa}

Immunized and non-immunized mice were intranasally challenged with $3 \times 10^{6}$ c.f.u. P. aeruginosa PAO1, and then survival was compared. All non-immunized mice died by day 2 post bacterial challenge, while $36 \%$ of immunized
No treatment

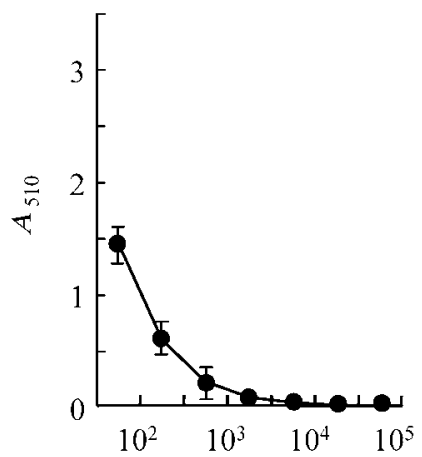

Adjuvant alone

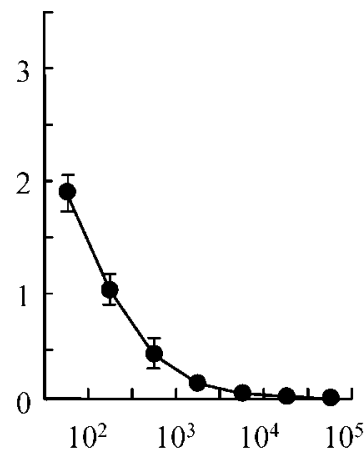

Dilution factor of serum
Immunized

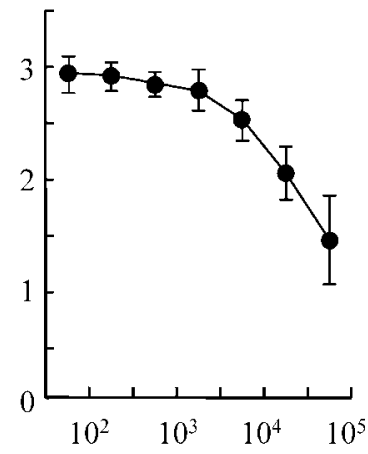
. 


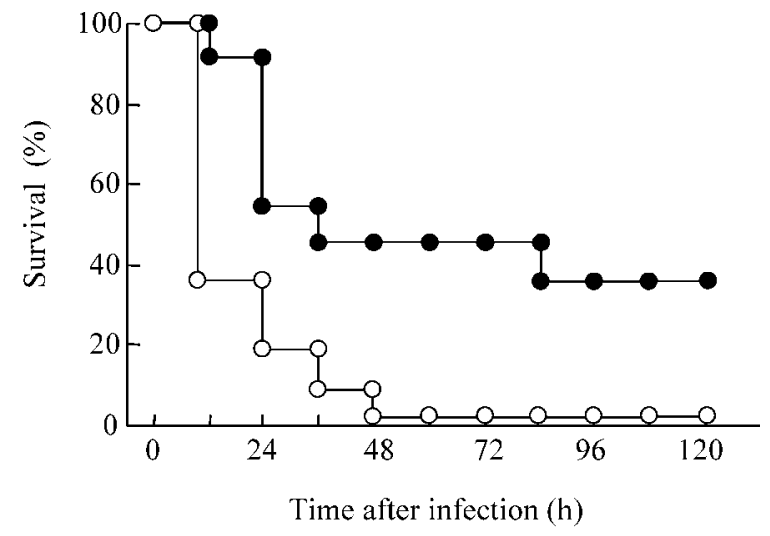

Fig. 3. Effects of vaccination against $3-\mathrm{oxo}_{-} \mathrm{C}_{12}-\mathrm{HSL}$ on survival of mice with acute pulmonary $P$. aeruginosa infection. $\mathrm{BALB} / \mathrm{c}$ mice were immunized with carrier-protein-conjugated 3-oxo- $\mathrm{C}_{12}$ - $\mathrm{HSL}(\bullet)$, and then $P$. aeruginosa PAO1 $\left(3.0 \times 10^{6}\right.$ c.f.u. per mouse) was introduced intranasally. The survival of control mice is also shown $(\bigcirc)$. The survival of mice was monitored for 7 days after infection $(n=11)$.

mice survived to day $4(P<0 \cdot 05)$ (Fig. 3). These data suggest that specific antibody against 3 -oxo- $\mathrm{C}_{12}$-HSL provides a survival benefit in mice infected with $P$. aeruginosa.

\section{Comparison of pulmonary bacterial numbers and TNF- $\alpha$ in immunized and non-immunized mice}

For a better understanding of the mechanisms of increase of survival in immunized mice, we compared pulmonary bacterial numbers and TNF- $\alpha$ levels in immunized and non-immunized mice $24 \mathrm{~h}$ after inoculation with bacteria $\left(9 \cdot 3 \times 10^{5}\right.$ c.f.u. per mouse) (Fig. 4$)$. Interestingly, bacterial numbers in the lungs were not different between the two groups, whereas the levels of TNF- $\alpha$ in the immunized mice were significantly lower than those of control mice $(P<0 \cdot 05)$. These results suggest that elaboration of specific antibody to 3 -oxo- $\mathrm{C}_{12}$-HSL is associated with survival benefit, probably through the blocking of host inflammatory responses, without affecting lung bacterial burden.

\section{Comparison of free 3-oxo- $\mathrm{C}_{12}$-HSL levels in serum and lung homogenate in immunized and non-immunized mice}

3 -oxo- $\mathrm{C}_{12}$-HSL levels in serum and lung homogenate were determined by ELISA. The 3-oxo- $\mathrm{C}_{12}$-HSL extractable by ethyl acetate was mainly in the free fraction rather than in the fraction bound to antibody. As shown in Fig. 5, free 3oxo- $\mathrm{C}_{12}$-HSL levels in serum and lung homogenates from immunized mice were about one-third and one-tenth those of non-immunized mice, respectively.

\section{Effects of immune serum on apoptosis of macrophages by 3-oxo- $\mathrm{C}_{12}-\mathrm{HSL}$}

Previously, we have reported that 3 -oxo- $\mathrm{C}_{12}$-HSL induces apoptosis in certain cells and cell lines, such as neutrophils and macrophages (Tateda et al., 2003). In a later study, we examined the effects of immune serum on the apoptosis of macrophage cell line P388D1 by 3-oxo- $\mathrm{C}_{12}-\mathrm{HSL}$. Although the concentration of autoinducers in the lungs of $P$. aeruginosa-infected patients remains unknown, we observed induction of apoptosis at $12 \mu \mathrm{M}$ or higher of 3-oxo- $\mathrm{C}_{12^{-}}$ HSL (Tateda et al., 2003). As shown in Fig. 6, 3-oxo- $\mathrm{C}_{12^{-}}$ HSL at a concentration of $50 \mu \mathrm{M}$ reduced cell viability to approximately $10 \%$ that of the control. Although the addition of non-immune serum induced no change in cell viability, immune serum at a concentration of $1 \%$ completely restored the reduction of viability effected by 3-oxo$\mathrm{C}_{12}$-HSL. These results suggest that specific antibody to 3-oxo- $\mathrm{C}_{12}$-HSL inhibits autoinducer-dependent apoptosis in macrophages.

\section{DISCUSSION}

These results demonstrated for the first time that specific antibody to 3 -oxo- $\mathrm{C}_{12}$-HSL plays a protective role in acute pulmonary $P$. aeruginosa infection. Interestingly, a reduction of pulmonary TNF- $\alpha$ was observed in immunized mice, without affecting bacterial burden in the lungs. Furthermore, the extractable 3 -oxo- $\mathrm{C}_{12}$-HSL levels in serum and lung were also reduced in immunized mice, as expected. This finding could be explained as a disturbance of the las autoinducing circuit by trapping extracellular
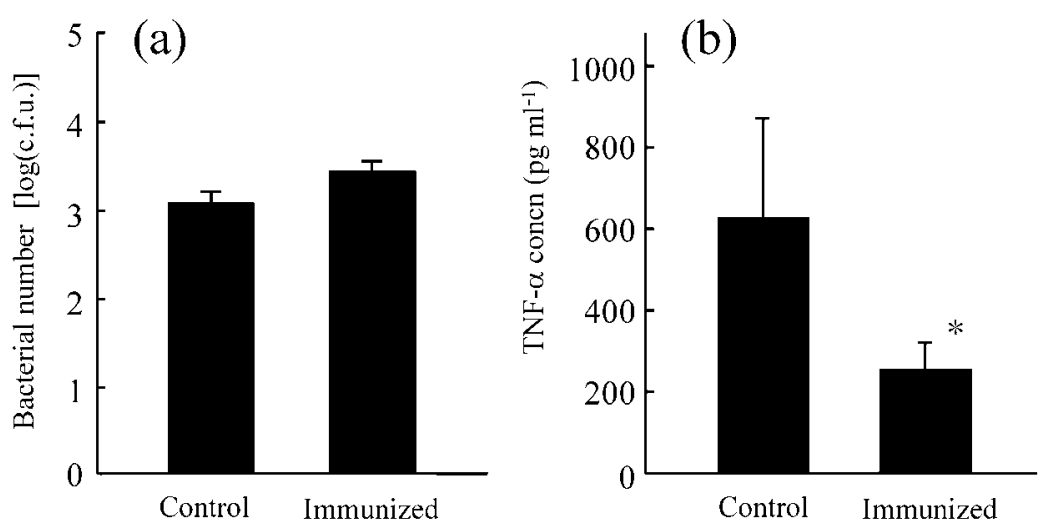

Fig. 4. Comparison of pulmonary bacterial
numbers and TNF- $\alpha$ levels in immunized and
non-immunized mice. Control and immunized
mice were intratracheally infected with $P$.
aeruginosa PAO1 $\left(9 \cdot 3 \times 10^{5}\right.$ c.f.u. per
mouse), and then bacterial number and
TNF- $\alpha$ levels in the lungs of mice were
examined $24 \mathrm{~h}$ after infection $(n=5)$. Data
were expressed as mean $\pm S E M .{ }^{*} P<0 \cdot 05$,
compared with control. 


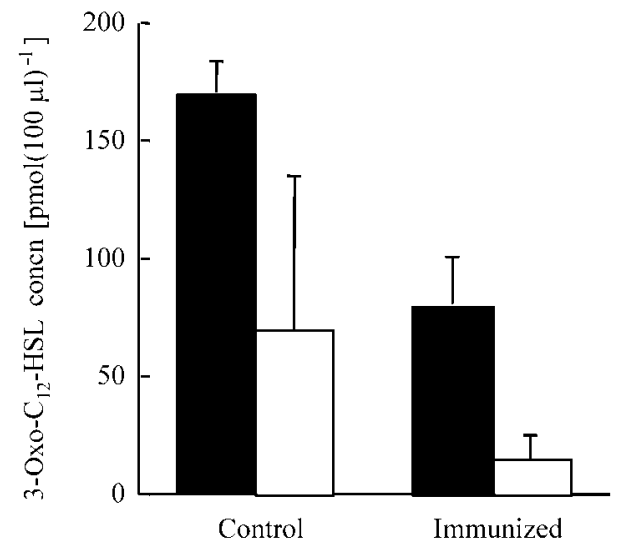

Fig. 5. Comparison of extractable $3-\mathrm{oxo}_{-}-\mathrm{C}_{12}-\mathrm{HSL}$ levels in serum and lung homogenate in immunized and non-immunized mice. Control and immunized mice were intratracheally infected with $P$. aeruginosa PAO1 $\left(9 \cdot 3 \times 10^{5}\right.$ c.f.u. per mouse), and then the extractable 3 -oxo- $\mathrm{C}_{12}-\mathrm{HSL}$ levels in the serum (black bars) and lung homogenates (white bars) of mice were determined $24 \mathrm{~h}$ after infection $(n=5)$. Data were expressed as mean \pm SEM.

3-oxo- $\mathrm{C}_{12}$-HSL with the antibody. These data are consistent with previous reports that the autoinducer 3-oxo$\mathrm{C}_{12}$-HSL is an extracellular molecule that plays a role in the cell-to-cell communication of bacteria and the expression of virulence factors in $P$. aeruginosa. The data also confirmed that the pathogen tightly bound to antibody is unable to exhibit its characteristic pathogenic action. The present results demonstrated the bacterial quorum-sensing system, especially autoinducer molecules, to be a novel

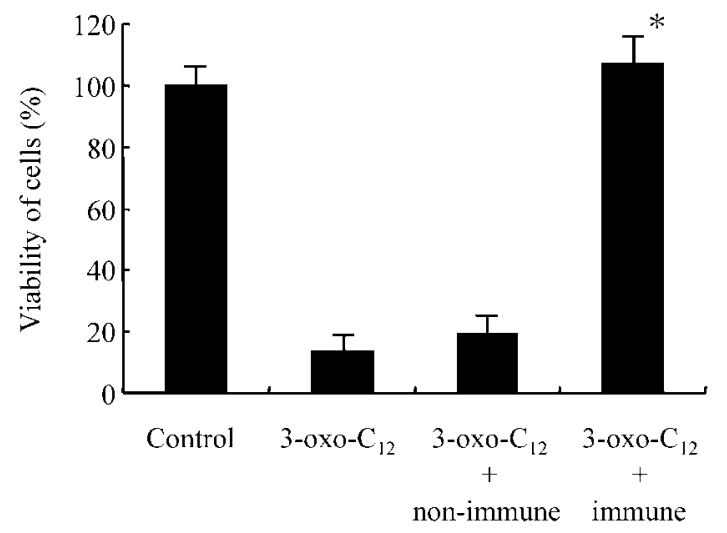

Fig. 6. Effects of immune serum on $3-\mathrm{oxo}_{-}-\mathrm{C}_{12}-\mathrm{HSL}$-induced apoptosis of macrophages. P388D1 cells were incubated with 3-oxo- $\mathrm{C}_{12}$-HSL (3-oxo- $\mathrm{C}_{12}, 50 \mu \mathrm{M}$ ) in the presence of immune or non-immune serum (1\%) for $24 \mathrm{~h}$, and then the viability of cells was examined by the TetraColor ONE assay $(n=5)$. Data were expressed as mean \pm SEM. ${ }^{*} P<0.05$, compared with control. candidate for vaccine development against $P$. aeruginosa infection.

Since the molecular mass of 3 -oxo- $\mathrm{C}_{12}$-HSL is approximately $300 \mathrm{Da}$, natural antibodies to this molecule may not be produced in animals and humans, even in individuals infected with $P$. aeruginosa. Therefore, we synthesized carrier protein-conjugated 3-oxo- $\mathrm{C}_{12}$-HSL, in which BSA was bound to the $\mathrm{C}_{12}$ position of the acyl side-chain. Immunization with this molecule led to high titres of specific antibody to 3 -oxo- $\mathrm{C}_{12}-\mathrm{HSL}$, and this was strongly associated with a survival benefit in mice with acute $P$. aeruginosa lung infection. The position of the conjugation of the carrier protein to 3 -oxo- $\mathrm{C}_{12}-\mathrm{HSL}$ may be important for maximum activity to induce specific antibody and protect mice from lethal infection. In this regard, additional experiments using a variety of techniques (e.g. direct conjugation of carrier protein to the HSL ring) are required to find optimal vaccine products. As an alternative approach to blocking bacterial autoinducers with specific antibodies, the development of mAbs against 3oxo- $\mathrm{C}_{12}$-HSL is promising, and this is now ongoing in our laboratory.

$P$. aeruginosa is known to produce a variety of virulence factors, such as exotoxin A, exoenzymes, pigments and LPS, and the expression of the vast majority of these factors is finely regulated through the production of the autoinducers 3-oxo-C 12 -HSL and $\mathrm{C}_{4}$-HSL (Van Delden \& Iglewski, 1998). Hartl and associates have reported significantly higher levels of proinflammatory cytokines, such as IL- $1 \beta$, IL- 6 and TNF- $\alpha$, in bronchoalveolar lavage fluid (BALF) of cystic fibrosis patients if the patients are infected with $P$. aeruginosa (Hartl et al., 2006). Wieland and collaborators have reported the comparative roles of Pseudomonas LPS, phospholipase $\mathrm{C}$ and exotoxin $\mathrm{A}$ in the induction of inflammatory cytokines in the lungs of mice (Wieland et al., 2002). The data demonstrate that LPS and phospholipase C, but not exotoxin A, are strong inducers of TNF- $\alpha$, IL- $1 \beta$ and IL6. In addition, the modulation of host inflammatory and immunological systems by bacterial autoinducers has been a recent topic of quorum-sensing research (Smith \& Iglewski, 2003a). In particular, 3-oxo- $\mathrm{C}_{12}$-HSL has been reported to possess a strong immunomodulatory activity, such as the inhibition of lymphocyte proliferation and TNF- $\alpha$ production (Chhabra et al., 2003; Telford et al., 1998). In this regard, we have reported that 3 -oxo- $\mathrm{C}_{12}$-HSL specifically induces apoptosis in certain cell types, including macrophages, a major cellular source of TNF- $\alpha$ (Tateda et al., 2003). Indeed, the reduction of viability of P388D1, a macrophage cell line, is induced by $50 \mu \mathrm{M} 3$-oxo- $\mathrm{C}_{12}$ $\mathrm{HSL}$, and this effect is completely inhibited in the presence of immune serum. Although the roles and significance of apoptosis in lungs with $P$. aeruginosa infection may be complex, these data suggest that the elaboration of specific antibody against 3 -oxo- $\mathrm{C}_{12}$-HSL may have dual effects on TNF- $\alpha$ production in the lungs, probably through the suppression of the expression of bacterial 
virulence factors and the modulation of host inflammatory responses.

The $P$. aeruginosa quorum-sensing system is a complex circuit, in which at least two cascades, 3-oxo- $\mathrm{C}_{12}$-HSLmediated Las and $\mathrm{C}_{4}$-HSL-mediated $\mathrm{Rhl}$, are involved (Parsek \& Greenberg, 2000; Tateda et al., 2004; Waters \& Bassler, 2005). The activation of the Las system mainly induces the production of elastase, while the Rhl system is associated with the induction of other sets of virulence factors, including pigments. These cascades are crossregulated by a variety of genes and factors. Interestingly, we observed an increase of pigment production in culture supernatants of $P$. aeruginosa when the bacteria were grown in the presence of 3-oxo- $\mathrm{C}_{12}$-HSL-blocking antibody (data not shown). Although we do not know a mechanism for the exaggerated production of pyocyanin in the setting of the blockade of the Las system, one possibility is that the blocking of the Las system cascade may change the balance of Las/Rhl, and that this results in exaggerated expression of the Rhl-mediated virulence factor pyocyanin (Diggle et al., 2002). These data suggest a limitation of a vaccination strategy targeting 3-oxo- $\mathrm{C}_{12}-\mathrm{HSL}$, and further support a rationale for total blockage of the bacterial quorum-sensing system, in which at least the Las and Rhl systems should be included.

As is well known, $P$. aeruginosa is a major cause of pulmonary damage and mortality in patients with cystic fibrosis, diffuse panbronchiolitis, and other forms of bronchiectasis (Hoiby, 1994; Wilson \& Dowling, 1998). In these lungs, the organism is found in microcolonies or biofilms, which are clusters of bacteria embedded in a matrix of polysaccharide (Lam et al., 1980; Singh et al., 2000). Although the concentration of autoinducers in the lungs of $P$. aeruginosa-infected patients remains unknown, $\mathrm{C}_{4}{ }^{-}$and 3 -oxo- $\mathrm{C}_{12}$-HSL have been detected in the sputum of these patients (Erickson et al., 2002; Storey et al., 1998). It has been shown that biofilms of $P$. aeruginosa grown in vitro can produce approximately $600 \mu \mathrm{M} 3$-oxo- $\mathrm{C}_{12}$-HSL, a concentration that is significantly higher than that earlier measured in planktonic cultures (Charlton et al., 2000). These data demonstrate a role for the quorum-sensing system in diseases of $P$. aeruginosa involving biofilms, and further suggest a necessity to evaluate vaccines against autoinducer molecules in chronic infection models. These projects are ongoing in our laboratory using an agar-bead model of end-bronchial pulmonary infection with a mucoid-type P. aeruginosa.

In conclusion, newer vaccine approaches targeting bacterial autoinducer molecules offer additional means to produce an effective immunotherapeutic reagent for this problematic pathogen. Further investigations of the optimal structure, formula and combination of immunogens for maximum induction of protective efficacy, in addition to safety and possible adverse reactions, may be necessary to confirm and construct a new vaccine strategy against $P$. aeruginosa infections.

\section{ACKNOWLEDGEMENTS}

We thank Hajime Hashimoto, Toho University School of Medicine, and Barbara H. Iglewski for their critical discussions and helpful suggestions. This work was supported by the Naito Foundation and grants from the Ministry of Education, Culture, Sports, Science and Technology of Japan.

\section{REFERENCES}

Baumann, U., Mansouri, E. \& von Specht, B. U. (2004). Recombinant OprF-OprI as a vaccine against Pseudomonas aeruginosa infections. Vaccine 22, 840-847.

Cachia, P. J. \& Hodges, R. S. (2003). Synthetic peptide vaccine and antibody therapeutic development: prevention and treatment of Pseudomonas aeruginosa. Biopolymers 71, 141-168.

Charlton, T. S., de Nys, R., Netting, A., Kumar, N., Hentzer, M., Givskov, M. \& Kjelleberg, S. (2000). A novel and sensitive method for the quantification of $\mathrm{N}$-3-oxoacyl homoserine lactones using gas chromatography-mass spectrometry: application to a model bacterial biofilm. Environ Microbiol 2, 530-541.

Chhabra, S. R., Harty, C., Hooi, D. S., Daykin, M., Williams, P., Telford, G., Pritchard, D. I. \& Bycroft, B. W. (2003). Synthetic analogues of the bacterial signal (quorum sensing) molecule $\mathrm{N}$-(3oxododecanoyl)-L-homoserine lactone as immune modulators. J Med Chem 46, 97-104.

Cryz, S. J., Jr, Furer, E., Cross, A. S., Wegmann, A., Germanier, R. \& Sadoff, J. C. (1987). Safety and immunogenicity of a Pseudomonas aeruginosa $O$-polysaccharide toxin A conjugate vaccine in humans. J Clin Invest 80, 51-56.

Diggle, S. P., Winzer, K., Lazdunski, A., Williams, P. \& Camara, M. (2002). Advancing the quorum in Pseudomonas aeruginosa: MvaT and the regulation of $\mathrm{N}$-acylhomoserine lactone production and virulence gene expression. J Bacteriol 184, 2576-2586.

DiMango, E., Zar, H. J., Bryan, R. \& Prince, A. (1995). Diverse Pseudomonas aeruginosa gene products stimulate respiratory epithelial cells to produce interleukin-8. J Clin Invest 96, 2204-2210.

Erickson, D. L., Endersby, R., Kirkham, A., Stuber, K., Vollman, D. D., Rabin, H. R., Mitchell, I. \& Storey, D. G. (2002). Pseudomonas aeruginosa quorum-sensing systems may control virulence factor expression in the lungs of patients with cystic fibrosis. Infect Immun 70, 1783-1790.

Fuqua, W. C., Winans, S. C. \& Greenberg, E. P. (1994). Quorum sensing in bacteria: the LuxR-LuxI family of cell density-responsive transcriptional regulators. J Bacteriol 176, 269-275.

Hartl, D., Griese, M., Kappler, M., Zissel, G., Reinhardt, D., Rebhan, C. Schendel, D. J. \& Krauss-Etschmann, S. (2006). Pulmonary $\mathrm{T}_{\mathrm{H}} 2$ response in Pseudomonas aeruginosa-infected patients with cystic fibrosis. J Allergy Clin Immunol 117, 204-211.

Hoiby, N. (1994). Diffuse panbronchiolitis and cystic fibrosis: East meets West. Thorax 49, 531-532.

Horikawa, M., Tateda, K., Tuzuki, E., Ishii, Y., Ueda, C., Takabatake, T., Miyairi, S., Yamaguchi, K. \& Ishiguro, M. (2006). Synthesis of Pseudomonas quorum-sensing autoinducer analogs and structural entities required for induction of apoptosis in macrophages. Bioorg Med Chem Lett 16, 2130-2133.

Hosoda, H., Sakai, Y., Yoshida, H., Miyairi, S., Ishii, K. \& Nambara, T. (1979). The preparation of steroid $N$-hydroxysuccinimide esters and their reactivities with bovine serum albumin. Chem Pharm Bull 27, 742-746.

Jones, R. J., Roe, E. A. \& Gupta, J. L. (1979). Controlled trials of a polyvalent Pseudomonas vaccine in burns. Lancet 2 (8150), 977-982. 
Kaplan, H. B. \& Greenberg, E. P. (1985). Diffusion of autoinducer is involved in regulation of the Vibrio fischeri luminescence system. $J$ Bacteriol 163, 1210-1214.

Lam, J., Chan, R., Lam, K. \& Costerton, J. W. (1980). Production of mucoid microcolonies by Pseudomonas aeruginosa within infected lungs in cystic fibrosis. Infect Immun 28, 546-556.

Miller, M. B. \& Bassler, B. L. (2001). Quorum sensing in bacteria. Annu Rev Microbiol 55, 165-199.

Mrsny, R. J., Daugherty, A. L., McKee, M. L. \& FitzGerald, D. J. (2002). Bacterial toxins as tools for mucosal vaccination. Drug Discov Today 7, 247-258.

Parsek, M. R. \& Greenberg, E. P. (2000). Acyl-homoserine lactone quorum sensing in Gram-negative bacteria: a signaling mechanism involved in associations with higher organisms. Proc Natl Acad Sci U S A 97, 8789-8793.

Pearson, J. P., Gray, K. M., Passador, L., Tucker, K. D., Eberhard, A., Iglewski, B. H. \& Greenberg, E. P. (1994). Structure of the autoinducer required for expression of Pseudomonas aeruginosa virulence genes. Proc Natl Acad Sci U S A 91, 197-201.

Pearson, J. P., Passador, L., Iglewski, B. H. \& Greenberg, E. P. (1995). A second $N$-acylhomoserine lactone signal produced by Pseudomonas aeruginosa. Proc Natl Acad Sci U S A 92, 1490-1494.

Pier, G. B. (1982). Safety and immunogenicity of high molecular weight polysaccharide vaccine from immunotype 1 Pseudomonas aeruginosa. J Clin Invest 69, 303-308.

Price, B. M., Barten Legutki, J., Galloway, D. R., von Specht, B. U., Gilleland, L. B., Gilleland, H. E., Jr \& Staczek, J. (2002). Enhancement of the protective efficacy of an oprF DNA vaccine against Pseudomonas aeruginosa. FEMS Immunol Med Microbiol 33, 89-99.

Richards, M. J., Edwards, J. R., Culver, D. H. \& Gaynes, R. P. (1999). Nosocomial infections in medical intensive care units in the United States. National Nosocomial Infections Surveillance System. Crit Care Med 27, 887-892.

Saleh, A., Figarella, C., Kammouni, W., Marchand-Pinatel, S., Lazdunski, A., Tubul, A., Brun, P. \& Merten, M. D. (1999). Pseudomonas aeruginosa quorum-sensing signal molecule $\mathrm{N}$-(3oxododecanoyl)-L-homoserine lactone inhibits expression of P2Y receptors in cystic fibrosis tracheal gland cells. Infect Immun 67, 5076-5082.

Sawa, T., Yahr, T. L., Ohara, M., Kurahashi, K., Gropper, M. A., Wiener-Kronish, J. P. \& Frank, D. W. (1999). Active and passive immunization with the Pseudomonas $\mathrm{V}$ antigen protects against type III intoxication and lung injury. Nat Med 5, 392-398.

Singh, P. K., Schaefer, A. L., Parsek, M. R., Moninger, T. O., Welsh, M. J. \& Greenberg, E. P. (2000). Quorum-sensing signals indicate that cystic fibrosis lungs are infected with bacterial biofilms. Nature 407, 762-764.

Smith, R. S. \& Iglewski, B. H. (2003a). P. aeruginosa quorum-sensing systems and virulence. Curr Opin Microbiol 6, 56-60.

Smith, R. S. \& Iglewski, B. H. (2003b). Pseudomonas aeruginosa quorum sensing as a potential antimicrobial target. J Clin Invest 112, 1460-1465.

Smith, R. S., Fedyk, E. R., Springer, T. A., Mukaida, N., Iglewski, B. H. \& Phipps, R. P. (2001). IL-8 production in human lung fibroblasts and epithelial cells activated by the Pseudomonas autoinducer
$\mathrm{N}$-3-oxododecanoyl homoserine lactone is transcriptionally regulated by NF- $\kappa$ B and activator protein-2. J Immunol 167, 366-374.

Smith, R. S., Kelly, R., Iglewski, B. H. \& Phipps, R. P. (2002). The Pseudomonas autoinducer $\mathrm{N}$-(3-oxododecanoyl) homoserine lactone induces cyclooxygenase- 2 and prostaglandin E2 production in human lung fibroblasts: implications for inflammation. J Immunol 169, 2636-2642.

Staczek, J., Gilleland, L. B., van der Heyde, H. C. \& Gilleland, H. E. (2003). DNA vaccines against chronic lung infections by Pseudomonas aeruginosa. FEMS Immunol Med Microbiol 37, 147-153.

Storey, D. G., Ujack, E. E., Rabin, H. R. \& Mitchell, I. (1998). Pseudomonas aeruginosa lasR transcription correlates with the transcription of las $A$, las $B$, and tox $A$ in chronic lung infections associated with cystic fibrosis. Infect Immun 66, 2521-2528.

Suga, H. \& Smith, K. M. (2003). Molecular mechanisms of bacterial quorum sensing as a new drug target. Curr Opin Chem Biol 7, 586-591.

Tateda, K., Comte, R., Pechere, J. C., Kohler, T., Yamaguchi, K. \& Van Delden, C. (2001). Azithromycin inhibits quorum sensing in Pseudomonas aeruginosa. Antimicrob Agents Chemother 45, 1930-1933.

Tateda, K., Ishii, Y., Horikawa, M., Matsumoto, T., Miyairi, S., Pechere, J. C., Standiford, T. J., Ishiguro, M. \& Yamaguchi, K. (2003). The Pseudomonas aeruginosa autoinducer $\mathrm{N}$-3-oxododecanoyl homoserine lactone accelerates apoptosis in macrophages and neutrophils. Infect Immun 71, 5785-5793.

Tateda, K., Takashima, K., Miyazaki, H., Matsumoto, T., Hatori, T. \& Yamaguchi, K. (1996). Noncompromised penicillin-resistant pneumococcal pneumonia CBA/J mouse model and comparative efficacies of antibiotics in this model. Antimicrob Agents Chemother 40, 1520-1525.

Tateda, K., Standiford, T. J., Pechere, J. C. \& Yamaguchi, K. (2004). Regulatory effects of macrolides on bacterial virulence: potential role as quorum-sensing inhibitors. Curr Pharm Des 10, 3055-3065.

Telford, G., Wheeler, D., Williams, P., Tomkins, P. T., Appleby, P., Sewell, H., Stewart, G. S., Bycroft, B. W. \& Pritchard, D. I. (1998). The Pseudomonas aeruginosa quorum-sensing signal molecule $\mathrm{N}$ (3-oxododecanoyl)-L-homoserine lactone has immunomodulatory activity. Infect Immun 66, 36-42.

Thomas, L. D., Kyd, J. M., Bastin, D. A., Dunkley, M. L. \& Cripps, A. W. (2003). Immunisation with non-integral OMPs promotes pulmonary clearance of Pseudomonas aeruginosa. FEMS Immunol Med Microbiol 37, 155-160.

Van Delden, C. \& Iglewski, B. H. (1998). Cell-to-cell signaling and Pseudomonas aeruginosa infections. Emerg Infect Dis 4, 551-560.

Waters, C. M. \& Bassler, B. L. (2005). Quorum sensing: cell-to-cell communication in bacteria. Annu Rev Cell Dev Biol 21, 319-346.

Whitehead, N. A., Barnard, A. M., Slater, H., Simpson, N. J. \& Salmond, G. P. (2001). Quorum-sensing in Gram-negative bacteria. FEMS Microbiol Rev 25, 365-404.

Wieland, C. W., Siegmund, B., Senaldi, G., Vasil, M. L., Dinarello, C. A. \& Fantuzzi, G. (2002). Pulmonary inflammation induced by Pseudomonas aeruginosa lipopolysaccharide, phospholipase C, and exotoxin A: role of interferon regulatory factor 1 . Infect Immun 70, 1352-1358.

Wilson, R. \& Dowling, R. B. (1998). Lung infections. 3. Pseudomonas aeruginosa and other related species. Thorax 53, 213-219. 